\title{
Model Regresi Nonparametrik Deret Fourier pada Pola Data Curah Hujan di Kota Mataram
}

\author{
Widiya Tri Astuti, ${ }^{a, *}$ Mustika Hadijati, Irwansyah \\ a Program Studi Matematika, FMIPA, Universitas Mataram, Jl. Majapahit No. 62, Mataram, 83125, Indonesia. Email: \\ widitrya96@gmail.com \\ b Program Studi Matematika, FMIPA, Universitas Mataram, Jl. Majapahit No. 62, Mataram, 83125, Indonesia. Email: \\ mustika.hadijati@unram.ac.id \\ c Program Studi Matematika, FMIPA, Universitas Mataram, Jl. Majapahit No. 62, Mataram, 83125, Indonesia. Email: \\ irw@unram.ac.id
}

A B S T R A C T

\begin{abstract}
Rainfall is one of the elements of the climate that has influence on people's lives in West Nusa Tenggara Province. The capital city of West Nusa Tenggara Province (NTB), namely the City of Mataram, in December 2016 was affected by flood disaster due the rainfall increation. This causes all activities in the City of Mataram paralyzed. This study aimed to modelling the rainfall and to determine the rainfall grade prediction in the City of Mataram in 2017. The method used was nonparametric regression of Fourier series. Based on the results of the analysis that has been committed, the best Fourier series of nonparametric regression model obtained at the Selaparang station was a model with 101 number of knots and 0.959116 value of $R^{2}$. For the Ampenan station, the best model obtained with 101 knots and 0.966992 value of $R^{2}$. As well as for the Cakranegara station, the best model obtained with 106 number of knots and 0.987778 value of $R^{2}$.
\end{abstract}

Keywords : GCV, knots, rainfall, $R^{2}$.

\section{Pendahuluan}

Model regresi nonparametrik deret Fourier adalah suatu model regresi nonparametrik yang digunakan dalam mengestimasi suatu pola data yang berbentuk trigonometri (Nurjanah, dkk., 2015). Pola data yang sesuai dengan pendekatan Fourier merupakan pola data yang berulang, yaitu pengulangan terhadap nilai variabel dependen untuk variabel independen yang berbeda-beda (Prahutama, 2013). Keadaan tersebut biasa disebut dengan pola musiman atau trend dimana banyak penelitian yang menggunakan data berulang (periodik) dalam menentukan metode penelitiannya.
Curah hujan adalah jumlah air yang jatuh di permukaan tanah datar selama periode tertentu yang diukur dengan satuan tinggi milimeter $(\mathrm{mm})$ di atas permukaan horizontal. Curah hujan merupakan salah satu unsur iklim yang memiliki pengaruh cukup besar bagi kehidupan manusia. Peningkatan curah hujan di suatu daerah berpotensi menimbulkan banjir, sebaliknya jika terjadi penurunan dari kondisi normalnya akan berpotensi terjadinya kekeringan. Kedua hal tersebut tentu akan berdampak buruk terhadap kelangsungan hidup manusia.

Oleh karena itu, tujuan dari penelitian ini adalah untuk menganalisis pola curah hujan di Kota Mataram dengan menggunakan deret Fourier. Hal ini didasarkan pada pola sebaran data curah hujan terhadap waktu yang

\footnotetext{
* Corresponding author.

Email: widitrya96@gmail.com
} 
mempengaruhinya menyebar secara berulang. Salah satu kelebihan pendekatan deret Fourier ini adalah mampu mengatasi data yang mempunyai sebaran trigonometri dan pola data berulang (fluktuatif), yaitu pengulangan nilai variabel dependen untuk variabel independen yang berbeda-beda (Prahutama, 2013).

\section{Landasan Teori}

\subsection{Analisis Regresi}

Analisis regresi merupakan studi ketergantungan satu atau lebih $\mathrm{X}$ (variabel bebas) terhadap $\mathrm{Y}$ (variabel terikat), dengan maksud untuk meramalkan nilai Y . Tujuan analisis regresi adalah mendapatkan pola hubungan secara matematis antara $\mathrm{X}$ dan $\mathrm{Y}$, mengetahui besarnya perubahan variabel $\mathrm{X}$ terhadap $\mathrm{Y}$ dan memprediksi $\mathrm{Y}$ jika nilai $X$ diketahui. Sehingga dalam suatu persamaan regresi terdapat dua macam variabel, yaitu variabel dependen (variabel terikat, respon) dan variabel independen (variabel bebas, prediktor). Terdapat tiga pendekatan dalam analisis regresi untuk mengestimasi kurva regresi, yaitu pendekatan parametrik, nonparametrik, dan semiparametrik.

\subsection{Regresi Nonparametrik}

Regresi nonparametrik merupakan suatu metode statistika yang digunakan untuk mengetahui hubungan antara variabel respon dengan variabel prediktor yang tidak diketahui asumsi bentuk fungsinya. Adapun model regresi nonparametrik secara umum dapat ditulis sebagai berikut.

$$
y_{i}=s\left(x_{i}\right)+\varepsilon_{i} \quad ; i=1,2,3, \ldots, n
$$

dengan,

$y_{i}=$ variabel dependen $\mathrm{ke}-i$

$x_{i}=$ variabel independen $\mathrm{ke}-i$

$s\left(x_{i}\right)=$ fungsi regresi nonparametrik yang tidak diketahui bentuknya

$\varepsilon_{i} \quad=$ error yang diasumsikan identik dan independen

\subsection{Regresi Nonparametrik Deret Fourier}

Model regresi nonparametrik deret Fourier adalah suatu model regresi nonparametrik yang digunakan dalam mengestimasi suatu pola data yang berbentuk trigonometri (Nurjanah, dkk., 2015). Fungsi $s\left(x_{i}\right)$ pada persamaan (1) merupakan kurva regresi yang tidak diketahui bentuknya dan dihampiri dengan menggunakan deret Fourier sebagai berikut.

$$
s\left(x_{i}\right)=\frac{1}{2} \alpha_{0}+\gamma_{j} x_{i j}+\sum_{k=1}^{K} \alpha_{j k} \cos k x_{i j}
$$

dengan,

$i=1,2, \ldots, n ; n=$ banyak pengamatan

$j=1,2, \ldots, m ; m=$ banyak variabelindependen

$k=1,2, \ldots, K \quad ; K=$ jumlah knot

$\alpha_{0}, \alpha_{k}, \gamma \quad=$ parameter - parameter dalam model

\subsection{Estimasi Parameter Ordinary Least Square (OLS)}

Diberikan data berpasangan $\left(y_{i}, x_{i j}\right)$ dengan $j=1,2, \ldots, m$ menyatakan banyaknya variabel independen dan $i=1,2, \ldots, n$ menyatakan banyaknya pengamatan. Model regresi nonparametrik deret Fourier jika disajikan dalam bentuk matriks diperoleh bentuk sebagai berikut (Prahutama, 2013).

$$
\mathbf{Y}=\mathbf{A} \boldsymbol{\theta}+\boldsymbol{\varepsilon}
$$

dengan,

$$
\begin{aligned}
& \mathbf{Y}=\left[\begin{array}{c}
Y_{1} \\
Y_{2} \\
Y_{3} \\
\vdots \\
Y_{n}
\end{array}\right]_{n x 1} \quad ; \quad \boldsymbol{\varepsilon}=\left[\begin{array}{c}
\varepsilon_{1} \\
\varepsilon_{2} \\
\varepsilon_{3} \\
\vdots \\
\varepsilon_{n}
\end{array}\right]_{n x 1} \\
& \boldsymbol{\theta}=\left[\begin{array}{llllllllllll}
\phi & \gamma_{1} & \alpha_{11} & \alpha_{12} & \cdots & \alpha_{1 k} & \cdots & \gamma_{m} & \alpha_{m 1} & \alpha_{m 2} & \cdots & \alpha_{m K}
\end{array}\right]^{T} 1 x(m(K+1)+1)
\end{aligned}
$$

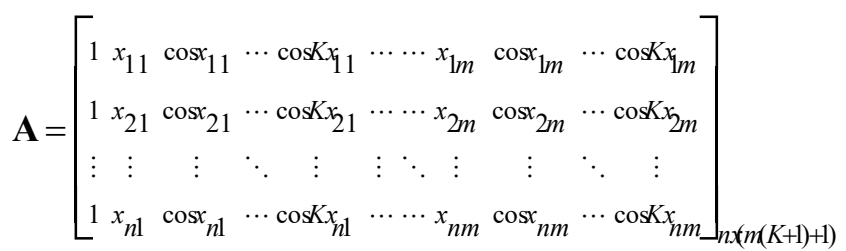

dengan $\phi=\frac{m}{2} \alpha_{0}$.

Estimasi untuk parameter $\theta$ diperoleh dengan menggunakan metode Ordinary Least Square (OLS). Jadi, diperoleh estimator deret Fourier sebagai berikut.

$$
\hat{\boldsymbol{\theta}}=\left(\mathbf{A}^{\mathrm{T}} \mathbf{A}\right)^{-1} \mathbf{A}^{\mathrm{T}} \mathbf{Y}
$$

Maka, estimasi untuk kurva regresi deret Fourier adalah sebagai berikut. 


$$
\begin{aligned}
\hat{s}\left(x_{i}\right) & =\mathbf{A} \hat{\boldsymbol{\theta}} \\
& =\mathbf{A}\left(\mathbf{A}^{\mathrm{T}} \mathbf{A}\right)^{-1} \mathbf{A}^{\mathrm{T}} \mathbf{Y} \\
& =\mathbf{H}[\mathbf{K}] \mathbf{Y}
\end{aligned}
$$

dengan,

$$
\mathbf{H}[\mathbf{K}]=\mathbf{A}\left(\mathbf{A}^{\mathrm{T}} \mathbf{A}\right)^{-1} \mathbf{A}^{\mathrm{T}} \mathbf{Y}
$$

Jika $\operatorname{det}\left(\mathbf{A}^{\mathrm{T}} \mathbf{A}\right)=0$ maka solusi dari persamaan (4) dapat diatasi dengan menggunakan matriks invers MoorePenrose dengan rumus sebagai berikut.

$$
\boldsymbol{\theta}=\mathbf{A}^{+} \mathbf{Y}
$$

dimana $\mathbf{A}^{+}$adalah matriks invers Moore-Penrose dari matriks A.

\subsection{Generalized Cross Validation (GCV)}

Pada pemodelan regresi nonparametrik dengan menggunakan deret Fourier, hal yang perlu diperhatikan adalah menentukan jumlah knot. Penentuan jumlah knot optimal biasa menggunakan metode GCV (Generalized Cross Validation). Menurut $\mathrm{Wu}$ dan Zhang dalam Fitriyani (2014), metode GCV secara umum didefinisikan sebagai berikut.

$$
G C V(K)=\frac{M S E(K)}{\left(n^{-1} \text { trace }[\mathbf{I}-\mathbf{H}(\mathbf{K})]\right)^{2}}
$$

dengan,

$$
\operatorname{MSE}(K)=\frac{1}{n} \sum_{i=1}^{n}\left(y_{i}-\hat{y}_{i}\right)^{2}
$$

dimana,

$\mathbf{I}=$ matriks identitas

$n \quad=$ banyak pengamatan

\section{$2.6 R^{2}$}

$$
R^{2}=\frac{J K R}{J K T}=\frac{\sum_{i=1}^{n}\left(\hat{y}_{i}-\bar{y}\right)^{2}}{\sum_{i=1}^{n}\left(y_{i}-\bar{y}\right)^{2}}
$$

bantuan software matematika R 3.4.3 dan Minitab 16 . Variabel-variabel yang digunakan yaitu curah hujan sebagai variabel dependen ( y ) dan waktu sebagai variabel independen ( $\mathrm{x}$ ).

Langkah-langkah pemodelan curah hujan di Kota Mataram menggunakan regresi nonparametrik deret Fourier antara lain sebagai berikut.

1. Studi literatur.

2. Membuat time series plot antara variabel dependen dengan variabel independen.

3. Memodelkan variabel dependen menggunakan regresi nonparametrik deret Fourier dengan berbagai jumlah knot.

4. Menghitung nilai GCV untuk masing-masing model regresi nonparametrik.

5. Menentukan jumlah knot optimal berdasarkan nilai GCV minimum.

6. Melakukan pemodelan menggunakan jumlah knot optimal.

7. Menghitung nilai estimasi parameter.

8. Menarik kesimpulan.
4. Hasil dan Pembahasan

\subsection{Time Series Plot antara Variabel Independen dengan Variabel Dependen}

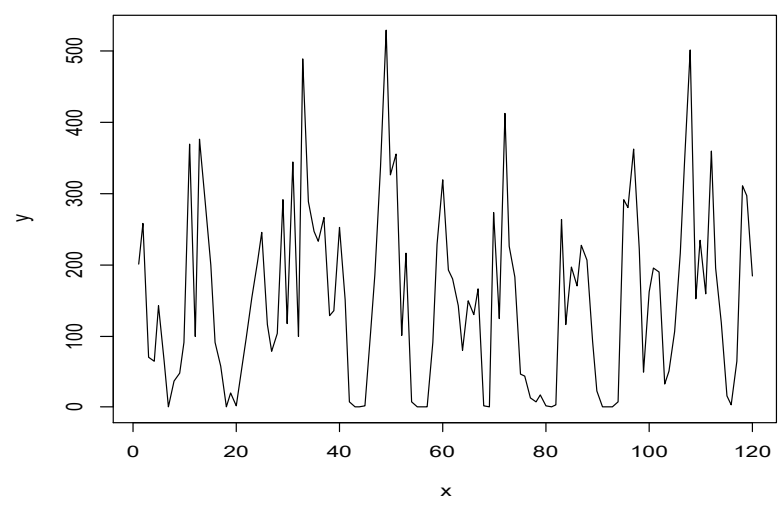

Time series plot data curah hujan Pos Selaparang

(a)

\section{Metode Penelitian}

Jenis data yang digunakan pada penelitian ini adalah data sekunder, yaitu data curah hujan di Kota Mataram pada rentang waktu 2008 - 2017 yang diperoleh dari BMKG (Badan Meteorologi, Klimatologi dan Geofisika) Kota Mataram. Data curah hujan tersebut diolah dengan 


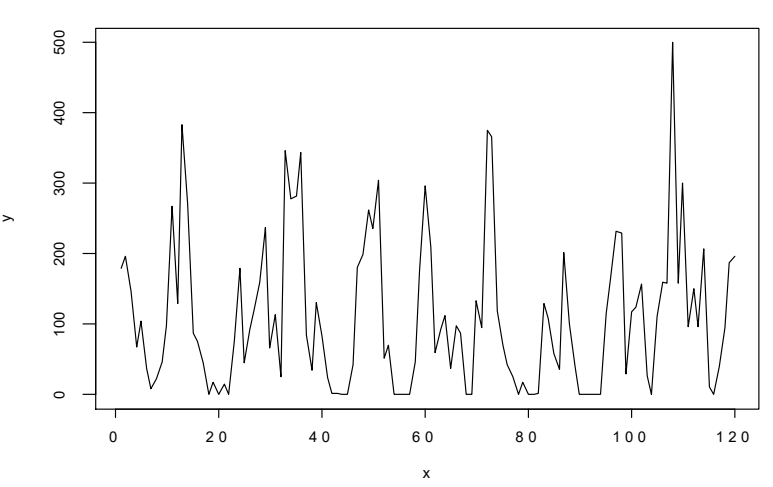

Time series plot data curah hujan Pos Ampenan

(b)

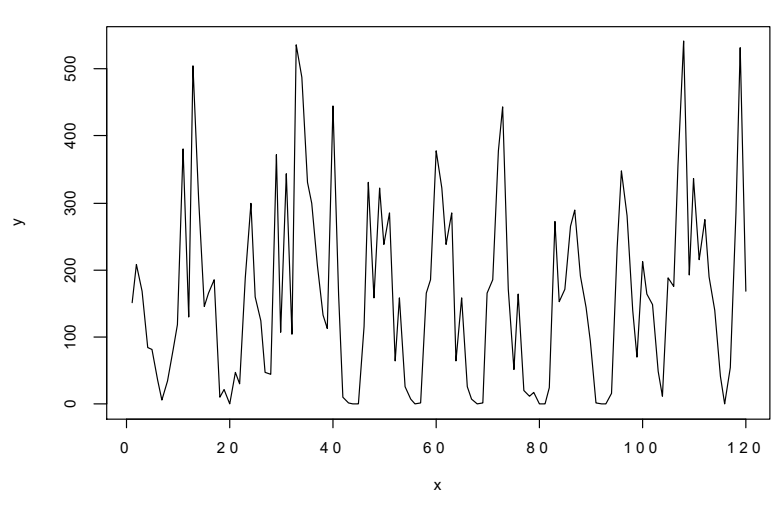

Time series plot data curah hujan Pos Cakranegara

(c)

Gambar 1. Time Series Plot antara Masing-masing Variabel Independen dengan Variabel Dependen

Dari semua time series plot (a), (b), dan (c) yang dihasilkan pada Gambar 1, secara visual dapat dilihat bahwa semua plot yang terbentuk membentuk pola data yang berulang yaitu pengulangan nilai variabel dependen untuk variabel independen yang berbeda-beda. Oleh karena itu, metode yang sesuai untuk mengestimasi model data ialah menggunakan regresi nonparametrik deret Fourier.

\subsection{Pemodelan Curah Hujan Pos Selaparang dengan Regresi Nonparametrik Deret Fourier}

Tabel 1. Nilai GCV dan $R^{2}$ untuk setiap K

\begin{tabular}{ccc}
3 & 16971,01 & 0,011367 \\
$\vdots$ & $\vdots$ & $\vdots$ \\
$\mathbf{1 0 1}$ & $\mathbf{3 2 1 1 6 , 3 4}$ & $\mathbf{0 , 9 5 9 1 1 6}$ \\
\hline
\end{tabular}

Pemilihan jumlah knot optimal dilihat dari jumlah knot yang memiliki nilai GCV paling minimum. Pada Tabel 1 dapat dilihat bahwa jumlah knot optimal yang dihasilkan adalah 1 dengan nilai GCV yang dihasilkan sebesar 16550,84. Akan tetapi, nilai $R^{2}$ yang dihasilkan untuk jumlah knot 1 sangat kecil yaitu 0,002017. Hal ini terjadi kemungkinan karena pada penelitian ini hanya menitikberatkan pada regresi nonparametrik deret Fourier tanpa melakukan penghalusan yaitu pemilihan parameter penghalus $(\lambda)$ yang dapat mengontrol kecocokan terhadap data dengan kemulusan kurva, sehingga pemilihan nilai $\mathrm{K}$ optimal berdasarkan nilai GCV minimum tidak dapat dilakukan. Oleh karena itu, untuk masing-masing jumlah knot dilihat nilai $R^{2}$ dari model (Asrini, 2013). Jumlah knot yang dipilih pada pos ini, yaitu 101 dengan nilai $R^{2}$ yang dihasilkan sebesar 0,959116 dan jumlah parameter yang diestimasi sebanyak 103 parameter.

Tabel 2. Hasil Estimasi Parameter untuk K = 101

\begin{tabular}{cc}
\hline Parameter & Nilai Estimasi \\
\hline$\hat{\alpha}_{0}$ & $-249,976$ \\
$\hat{\gamma}$ & 4,651 \\
$\hat{\alpha}_{1}$ & 128,419 \\
$\vdots$ & $\vdots$ \\
$\hat{\alpha}_{101}$ & 96,436 \\
\hline
\end{tabular}

Model yang diperoleh untuk pos Selaparang dengan 101 jumlah knot dan 1 variabel independen adalah sebagai berikut.

$$
\begin{aligned}
\hat{y}_{i}= & \frac{1}{2} \alpha_{0}+\gamma_{j} x_{i j}+\sum_{k=1}^{101} \alpha_{j k} \cos k x_{i j} \\
= & \frac{1}{2} \alpha_{0}+\gamma_{j} x_{i j}+\left(\alpha_{j 1} \cos x_{i j}+\alpha_{j 2} \cos 2 x_{i j}\right. \\
& \left.+\ldots+\alpha_{j 101} \cos 101 x_{i j}\right) \\
= & -249,976+4,651 x+128,419 \cos x-26,005 \cos 2 x \\
& -13,844 \cos 3 x+\ldots+6,925 \cos 99 x+197,768 \cos 100 x \\
& +96,436 \cos 101 x
\end{aligned}
$$

Berikut grafik data curah hujan pos Selaparang dengan deret Fourier.

\begin{tabular}{ccc}
\hline Knot & GCV & $R^{2}$ \\
\hline $\mathbf{1}$ & $\mathbf{1 6 5 5 0 , 8 4}$ & $\mathbf{0 , 0 0 2 0 1 7}$ \\
2 & 16813,62 & 0,003428
\end{tabular}




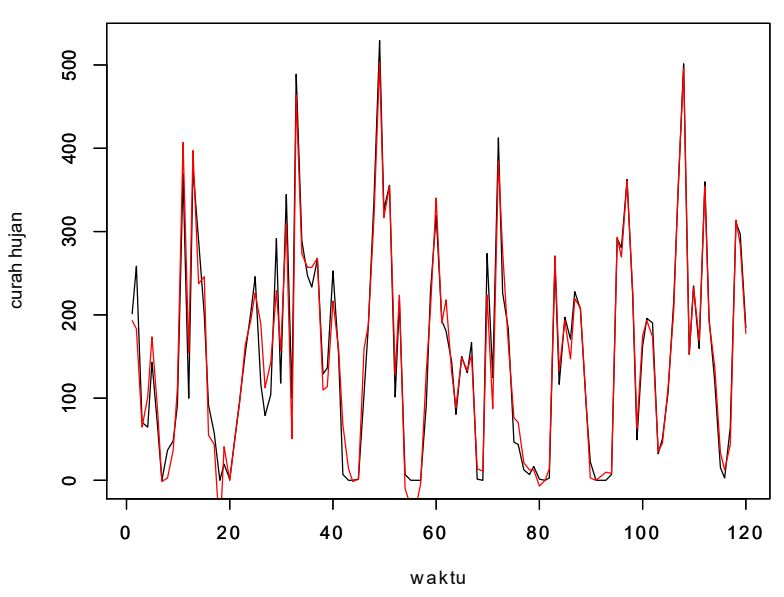

Gambar 2. Grafik Curah Hujan Pos Selaparang dengan deret Fourier

Berdasarkan Gambar 2 dapat dilihat bahwa garis hitam pada gambar tersebut menunjukkan jumlah curah hujan aktual, sedangkan garis merah menunjukkan jumlah knot yang digunakan. Dapat diketahui bahwa curah hujan tertinggi terjadi pada bulan Januari tahun 2012 dengan jumlah curah hujan $502,586 \mathrm{~mm}$ per tahun, sedangkan curah hujan terendah terjadi pada bulan Juni tahun 2009 dengan jumlah curah hujan $-65,988 \mathrm{~mm}$ per tahun. Dimana pada penelitian ini jumlah curah hujan yang bernilai negatif dianggap sebagai bulan kering atau tidak ada hujan.

\subsection{Pemodelan Curah Hujan Pos Ampenan dengan Regresi Nonparametrik Deret Fourier}

Tabel 3. Nilai GCV dan $R^{2}$ untuk setiap K

\begin{tabular}{ccc}
\hline Knot & GCV & $R^{2}$ \\
\hline $\mathbf{1}$ & $\mathbf{1 1 5 7 2 . 1 1}$ & $\mathbf{0 . 0 0 6 3 7 5}$ \\
2 & 11750.09 & 0.008265 \\
3 & 11749.45 & 0.025344 \\
$\vdots$ & $\vdots$ & $\vdots$ \\
$\mathbf{1 0 1}$ & $\mathbf{1 8 2 0 9 . 1 3}$ & $\mathbf{0 . 9 6 6 9 9 2}$ \\
\hline
\end{tabular}

Jumlah knot yang dipilih pada pos ini, yaitu 101 dengan nilai $R^{2}$ yang dihasilkan sebesar 0,966992 dan jumlah parameter yang diestimasi sebanyak 103 parameter.

Tabel 4. Hasil Estimasi Parameter untuk $\mathrm{K}=101$

\begin{tabular}{cc}
\hline Parameter & Nilai Estimasi \\
\hline$\hat{\alpha}_{0}$ & 111,047 \\
$\hat{\gamma}$ & $-0,771$ \\
$\hat{\alpha}_{1}$ & 116,747
\end{tabular}

\begin{tabular}{cc}
$\vdots$ & $\vdots$ \\
$\hat{\alpha}_{101}$ & 81,864 \\
\hline
\end{tabular}

Model yang diperoleh untuk pos Ampenan dengan 101 jumlah knot dan 1 variabel independen adalah sebagai berikut.

$$
\begin{aligned}
\hat{y}_{i}= & \frac{1}{2} \alpha_{0}+\gamma_{j} x_{i j}+\sum_{k=1}^{101} \alpha_{j k} \cos k x_{i j} \\
= & \frac{1}{2} \alpha_{0}+\gamma_{j} x_{i j}+\left(\alpha_{j 1} \cos x_{i j}+\alpha_{j 2} \cos 2 x_{i j}\right. \\
& \left.+\ldots+\alpha_{j 101} \cos 101 x_{i j}\right) \\
= & 111,047-0,771 x+116,747 \cos x-18,068 \cos 2 x \\
& -41,764 \cos 3 x-\ldots-21,336 \cos 99 x+153,990 \cos 100 x \\
& +81,864 \cos 101 x
\end{aligned}
$$

Berikut grafik data curah hujan pos Ampenan dengan deret Fourier.

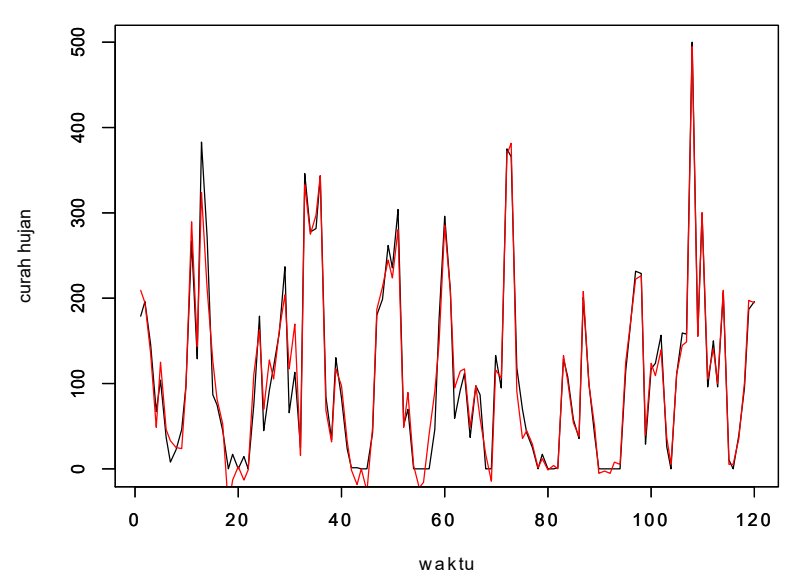

Gambar 3. Grafik Curah Hujan Pos Ampenan dengan deret Fourier

Berdasarkan Gambar 3 dapat dilihat bahwa garis hitam pada gambar tersebut menunjukkan jumlah curah hujan aktual, sedangkan garis merah menunjukkan jumlah knot yang digunakan. Dapat diketahui bahwa curah hujan tertinggi terjadi pada bulan Desember tahun 2016 dengan jumlah curah hujan 495,528 mm per tahun, sedangkan curah hujan terendah terjadi pada bulan Juni tahun 2009 dengan jumlah curah hujan $-45,523 \mathrm{~mm}$ per tahun.

\subsection{Pemodelan Curah Hujan Pos Cakranegara dengan Regresi Nonparametrik Deret Fourier}

Tabel 5. Nilai GCV dan $R^{2}$ untuk setiap $\mathrm{K}$ 


\begin{tabular}{ccc}
\hline Knot & GCV & $R^{2}$ \\
\hline $\mathbf{1}$ & $\mathbf{2 0 1 8 3 . 1 9}$ & $\mathbf{0 . 0 0 2 6 4 0}$ \\
2 & 20518.65 & 0.003321 \\
3 & 20875.71 & 0.003385 \\
$\vdots$ & $\vdots$ & $\vdots$ \\
$\mathbf{1 0 6}$ & $\mathbf{2 3 5 1 1 . 6 4}$ & $\mathbf{0 . 9 8 7 7 7 8}$ \\
\hline
\end{tabular}

Jumlah knot yang dipilih pada pos ini, yaitu 106 dengan nilai $R^{2}$ yang dihasilkan sebesar 0,987778 dan jumlah parameter yang diestimasi sebanyak 108 parameter.

Tabel 6. Hasil Estimasi Parameter untuk K = 106

\begin{tabular}{cc}
\hline Parameter & Nilai Estimasi \\
\hline$\hat{\alpha}_{0}$ & $-55,110$ \\
$\hat{\gamma}$ & 1,928 \\
$\hat{\alpha}_{1}$ & 211,311 \\
$\vdots$ & $\vdots$ \\
$\hat{\alpha}_{106}$ & 70,230 \\
\hline
\end{tabular}

Model yang diperoleh untuk pos Cakranegara dengan 106 jumlah knot dan 1 variabel independen adalah sebagai berikut.

$$
\begin{aligned}
\hat{y}_{i}= & \frac{1}{2} \alpha_{0}+\gamma_{j} x_{i j}+\sum_{k=1}^{106} \alpha_{j k} \cos k x_{i j} \\
= & \frac{1}{2} \alpha_{0}+\gamma_{j} x_{i j}+\left(\alpha_{j 1} \cos x_{i j}+\alpha_{j 2} \cos 2 x_{i j}\right. \\
& \left.+\ldots+\alpha_{j 106} \cos 106 x_{i j}\right) \\
= & -55,110+1,928 x+211,311 \cos x-57,173 \cos 2 x \\
& +7,665 \cos 3 x+\ldots+46,706 \cos 104 x-18,813 \cos 105 x \\
& +70,230 \cos 106 x
\end{aligned}
$$

Berikut grafik data curah hujan pos Cakranegara dengan deret Fourier.

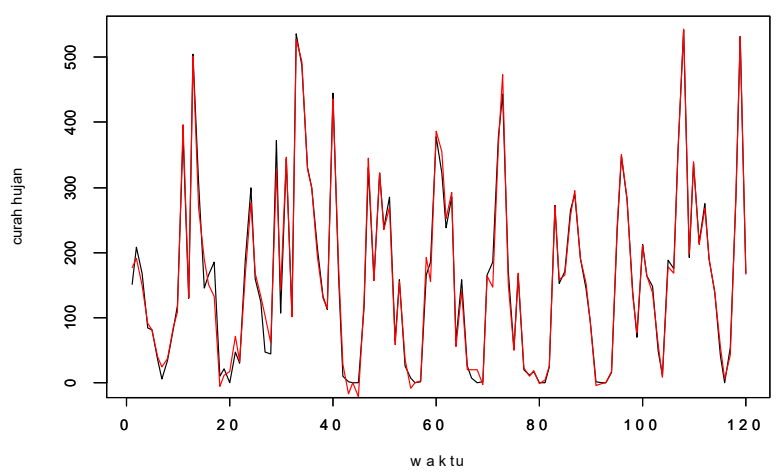

Gambar 4. Grafik Curah Hujan Pos Cakranegara dengan deret Fourier
Berdasarkan Gambar 4 dapat dilihat bahwa garis hitam pada gambar tersebut menunjukkan jumlah curah hujan aktual, sedangkan garis merah menunjukkan jumlah knot yang digunakan. Dapat diketahui bahwa curah hujan tertinggi terjadi pada bulan Desember tahun 2016 dengan jumlah curah hujan $542,863 \mathrm{~mm}$ per tahun, sedangkan curah hujan terendah terjadi pada bulan September tahun 2011 dengan jumlah curah hujan -21,092 mm per tahun.

\section{Kesimpulan}

Berdasarkan hasil dan pembahasan yang telah dilakukan, maka kesimpulan yang diperoleh yaitu model regresi nonparametrik deret Fourier terbaik untuk pemodelan curah hujan di Kota Mataram pada tiap lokasi pos hujan adalah sebagai berikut.

a. Pos hujan Selaparang dengan $\mathrm{K}=101$ dan $R^{2}=$ 0,959116, model yang dihasilkan adalah sebagai berikut.

$$
\begin{aligned}
\hat{y}_{i}= & \frac{1}{2} \alpha_{0}+\gamma_{j} x_{i j}+\sum_{k=1}^{101} \alpha_{j k} \cos k x_{i j} \\
= & \frac{1}{2} \alpha_{0}+\gamma_{j} x_{i j}+\left(\alpha_{j 1} \cos x_{i j}+\alpha_{j 2} \cos 2 x_{i j}\right. \\
& \left.+\ldots+\alpha_{j 101} \cos 101 x_{i j}\right) \\
= & -249,976+4,651 x+128,419 \cos x-26,005 \cos 2 x \\
& -13,844 \cos 3 x-\ldots+6,925 \cos 99 x+197,768 \cos 100 x \\
& +96,436 \cos 101 x
\end{aligned}
$$

b. Pos hujan Ampenan dengan $\mathrm{K}=101$ dan $R^{2}=$ 0,966992, model yang dihasilkan adalah sebagai berikut.

$$
\begin{aligned}
\hat{y}_{i}= & \frac{1}{2} \alpha_{0}+\gamma_{j} x_{i j}+\sum_{k=1}^{101} \alpha_{j k} \cos k x_{i j} \\
= & \frac{1}{2} \alpha_{0}+\gamma_{j} x_{i j}+\left(\alpha_{j 1} \cos x_{i j}+\alpha_{j 2} \cos 2 x_{i j}\right. \\
& \left.+\ldots+\alpha_{j 101} \cos 101 x_{i j}\right) \\
= & -111,047-0,771 x+116747 \cos x-18,068 \cos 2 x \\
& \quad-41,764 \cos 3 x-\ldots 21,336 \cos 99 x+153,990 \cos 100 x \\
& +81,864 \cos 101 x
\end{aligned}
$$

c. Pos hujan Cakranegara dengan $\mathrm{K}=106$ dan $R^{2}=$ 0,987778, model yang dihasilkan adalah sebagai berikut. 


$$
\begin{aligned}
\hat{y}_{i}= & \frac{1}{2} \alpha_{0}+\gamma_{j} x_{i j}+\sum_{k=1}^{106} \alpha_{j k} \cos k x_{i j} \\
= & \frac{1}{2} \alpha_{0}+\gamma_{j} x_{i j}+\left(\alpha_{j 1} \cos x_{i j}+\alpha_{j 2} \cos 2 x_{i j}\right. \\
& \left.+\ldots+\alpha_{j 106} \cos 106 x_{i j}\right) \\
= & -55,110+1,928 x+211,311 \cos x-57,173 \cos 2 x \\
& +7,665 \cos 3 x+\ldots+46,706 \cos 104 x+18,183 \cos 105 x \\
& +70,230 \cos 106 x
\end{aligned}
$$

\section{DAFTAR PUSTAKA}

Asrini. L.J., 2013, Model Regresi Semiparametrik Deret Fourier, Tesis, Program Magister Jurusan Statistika, FMIPA Institut Teknologi Sepuluh Nopember,
Surabaya.

Fitriyani, N., 2014, Metode Cross Validation dan Generalized Cross Validation Dalam Regresi Nonparametrik Spline, Tesis, Program Magister Jurusan Statistika FMIPA ITS, Surabaya.

Nurjanah, F., dkk., 2015, Model Regresi Nonparametrik dengan Pendekatan Deret Fourier pada Pola Data Curah Hujan di Kota Semarang, Jurnal Statistika, Vol. 3, No. 2, 8-14, Universitas Muhammadiyah, Semarang.

Prahutama, A., 2013, Model Regresi Nonparametrik dengan Pendekatan Deret Fourier pada Kasus Tingkat Pengangguran Terbuka di Jawa Timur, Prosiding Seminar Nasional Statistika Universitas Diponegoro, ISBN : 978-602-14387-0-1. 


\section{LAMPIRAN}

Lampiran 1. Ringkasan Nilai GCV dan $R^{2}$ Regresi Nonparametrik Deret Fourier Pos Selaparang dengan 101 Jumlah Knot

\begin{tabular}{|c|c|c|c|c|c|c|c|c|}
\hline Knot & GCV & $R^{2}$ & Knot & GCV & $R^{2}$ & Knot & $\mathrm{GCV}$ & $R^{2}$ \\
\hline 1 & 16550.84 & 0.002017 & 35 & 28428.40 & 0.137339 & 69 & 57283.18 & 0.394170 \\
\hline 2 & 16813.62 & 0.003428 & 36 & 29065.41 & 0.139134 & 70 & 59330.43 & 0.397868 \\
\hline 3 & 16971.01 & 0.011367 & 37 & 29140.43 & 0.157834 & 71 & 61748.29 & 0.399169 \\
\hline 4 & 17261.30 & 0.011869 & 38 & 29072.25 & 0.180422 & 72 & 64453.81 & 0.399247 \\
\hline 5 & 17350.88 & 0.024090 & 39 & 29760.79 & 0.181855 & 73 & 67115.48 & 0.401341 \\
\hline 6 & 17576.41 & 0.028824 & 40 & 30482.24 & 0.183103 & 74 & 70189.00 & 0.401442 \\
\hline 7 & 17763.93 & 0.035912 & 41 & 31091.27 & 0.188009 & 75 & 70312.34 & 0.427336 \\
\hline 8 & 18088.34 & 0.035914 & 42 & 31913.43 & 0.188045 & 76 & 66661.79 & 0.482027 \\
\hline 9 & 18387.64 & 0.037700 & 43 & 32722.56 & 0.189223 & 77 & 67314.35 & 0.501567 \\
\hline 10 & 18685.32 & 0.039982 & 44 & 33582.51 & 0.189957 & 78 & 70292.60 & 0.504594 \\
\hline 11 & 19035.88 & 0.039998 & 45 & 33472.44 & 0.214286 & 79 & 73935.57 & 0.504648 \\
\hline 12 & 19075.40 & 0.055902 & 46 & 34379.04 & 0.214963 & 80 & 77878.00 & 0.504649 \\
\hline 13 & 19417.80 & 0.057003 & 47 & 34819.36 & 0.226841 & 81 & 73656.98 & 0.555830 \\
\hline 14 & 19787.60 & 0.057262 & 48 & 35799.12 & 0.227320 & 82 & 74793.30 & 0.573028 \\
\hline 15 & 20046.19 & 0.063220 & 49 & 36707.35 & 0.230191 & 83 & 79083.77 & 0.573268 \\
\hline 16 & 20165.13 & 0.075870 & 50 & 36900.67 & 0.248406 & 84 & 83800.09 & 0.573289 \\
\hline 17 & 20532.22 & 0.077407 & 51 & 38008.21 & 0.248449 & 85 & 88937.60 & 0.573376 \\
\hline 18 & 20920.48 & 0.078483 & 52 & 38983.55 & 0.252001 & 86 & 92439.75 & 0.583044 \\
\hline 19 & 21257.97 & 0.082252 & 53 & 40019.64 & 0.255214 & 87 & 96006.86 & 0.593597 \\
\hline 20 & 21653.83 & 0.083952 & 54 & 39718.98 & 0.283379 & 88 & 100583.00 & 0.601252 \\
\hline 21 & 21959.16 & 0.089897 & 55 & 40932.56 & 0.284382 & 89 & 84246.92 & 0.687909 \\
\hline 22 & 22187.75 & 0.099286 & 56 & 41806.88 & 0.292115 & 90 & 90365.57 & 0.687931 \\
\hline 23 & 22629.37 & 0.100396 & 57 & 43098.10 & 0.293602 & 91 & 96917.04 & 0.688786 \\
\hline 24 & 23112.91 & 0.100416 & 58 & 43738.01 & 0.306426 & 92 & 104106.00 & 0.690006 \\
\hline 25 & 23593.50 & 0.101145 & 59 & 45131.70 & 0.307982 & 93 & 111614.90 & 0.692720 \\
\hline 26 & 24098.82 & 0.101532 & 60 & 46562.14 & 0.310045 & 94 & 115068.30 & 0.708049 \\
\hline 27 & 24568.94 & 0.103809 & 61 & 47793.26 & 0.316013 & 95 & 116317.20 & 0.728961 \\
\hline 28 & 24983.24 & 0.108615 & 62 & 48097.47 & 0.335600 & 96 & 121502.70 & 0.740962 \\
\hline 29 & 25528.06 & 0.109304 & 63 & 47523.08 & 0.366770 & 97 & 123179.20 & 0.760719 \\
\hline 30 & 26099.84 & 0.109704 & 64 & 48741.92 & 0.373932 & 98 & 134269.20 & 0.763425 \\
\hline 31 & 26629.52 & 0.112163 & 65 & 50485.18 & 0.375335 & 99 & 148384.90 & 0.764045 \\
\hline 32 & 26522.39 & 0.135946 & 66 & 51599.69 & 0.385410 & 100 & 59494.84 & 0.915091 \\
\hline 33 & 27135.79 & 0.136402 & 67 & 53525.35 & 0.386759 & 101 & 32116.34 & 0.959116 \\
\hline 34 & 27770.17 & 0.136885 & 68 & 55195.80 & 0.392176 & & & \\
\hline
\end{tabular}


Lampiran 2. Ringkasan Nilai GCV dan $R^{2}$ Regresi Nonparametrik Deret Fourier Pos Ampenan dengan 101 Jumlah Knot

\begin{tabular}{|c|c|c|c|c|c|c|c|c|}
\hline Knot & GCV & $R^{2}$ & Knot & GCV & $R^{2}$ & Knot & GCV & $R^{2}$ \\
\hline 1 & 11572.11 & 0.006375 & 35 & 19692.40 & 0.149072 & 69 & 35626.69 & 0.463455 \\
\hline 2 & 11750.09 & 0.008265 & 36 & 19923.38 & 0.159710 & 70 & 36686.58 & 0.469814 \\
\hline 3 & 11749.45 & 0.025344 & 37 & 20408.86 & 0.160101 & 71 & 37961.70 & 0.474007 \\
\hline 4 & 11956.41 & 0.025350 & 38 & 20289.77 & 0.185492 & 72 & 39610.19 & 0.474272 \\
\hline 5 & 12097.91 & 0.031040 & 39 & 20771.05 & 0.186887 & 73 & 41307.89 & 0.475318 \\
\hline 6 & 12103.79 & 0.047652 & 40 & 21274.99 & 0.188111 & 74 & 43168.00 & 0.475790 \\
\hline 7 & 12309.86 & 0.048656 & 41 & 21793.40 & 0.189516 & 75 & 43064.69 & 0.500545 \\
\hline 8 & 12534.24 & 0.048691 & 42 & 22270.16 & 0.193157 & 76 & 40677.90 & 0.549914 \\
\hline 9 & 12696.19 & 0.053840 & 43 & 22857.05 & 0.193544 & 77 & 42370.54 & 0.553245 \\
\hline 10 & 12927.57 & 0.054193 & 44 & 23388.42 & 0.196654 & 78 & 43810.79 & 0.560317 \\
\hline 11 & 13134.33 & 0.056779 & 45 & 23437.64 & 0.216574 & 79 & 45994.42 & 0.561194 \\
\hline 12 & 13265.30 & 0.065096 & 46 & 23891.79 & 0.223124 & 80 & 48172.81 & 0.563678 \\
\hline 13 & 13519.08 & 0.065102 & 47 & 24195.41 & 0.234953 & 81 & 46169.16 & 0.603545 \\
\hline 14 & 13779.01 & 0.065191 & 48 & 24617.29 & 0.243386 & 82 & 47944.03 & 0.610258 \\
\hline 15 & 13955.77 & 0.071319 & 49 & 25319.30 & 0.243885 & 83 & 50500.74 & 0.611964 \\
\hline 16 & 14094.50 & 0.080211 & 50 & 25208.92 & 0.268844 & 84 & 53450.68 & 0.612431 \\
\hline 17 & 14346.31 & 0.082046 & 51 & 25966.68 & 0.268854 & 85 & 56709.08 & 0.612637 \\
\hline 18 & 14633.97 & 0.082090 & 52 & 26656.19 & 0.271677 & 86 & 60245.69 & 0.613042 \\
\hline 19 & 14802.36 & 0.090004 & 53 & 27482.51 & 0.271682 & 87 & 62883.04 & 0.620951 \\
\hline 20 & 15101.06 & 0.090301 & 54 & 27389.93 & 0.296297 & 88 & 66979.96 & 0.621884 \\
\hline 21 & 15414.02 & 0.090301 & 55 & 28250.95 & 0.296681 & 89 & 54406.35 & 0.712999 \\
\hline 22 & 15707.37 & 0.092003 & 56 & 28825.82 & 0.304970 & 90 & 57137.00 & 0.719022 \\
\hline 23 & 15848.64 & 0.102824 & 57 & 29576.18 & 0.309697 & 91 & 60777.04 & 0.722089 \\
\hline 24 & 16181.75 & 0.103151 & 58 & 30092.44 & 0.320486 & 92 & 65538.63 & 0.722104 \\
\hline 25 & 16526.02 & 0.103454 & 59 & 30990.78 & 0.323333 & 93 & 70672.34 & 0.722944 \\
\hline 26 & 16762.56 & 0.110073 & 60 & 32040.67 & 0.323923 & 94 & 67516.31 & 0.756068 \\
\hline 27 & 16929.74 & 0.120630 & 61 & 33065.88 & 0.326143 & 95 & 64466.26 & 0.786092 \\
\hline 28 & 17298.96 & 0.121092 & 62 & 33382.81 & 0.343345 & 96 & 69565.02 & 0.788809 \\
\hline 29 & 17666.20 & 0.122269 & 63 & 31546.21 & 0.401436 & 97 & 74905.29 & 0.792800 \\
\hline 30 & 18012.43 & 0.125065 & 64 & 32303.43 & 0.409154 & 98 & 82547.51 & 0.792890 \\
\hline 31 & 18085.35 & 0.141375 & 65 & 33274.80 & 0.413720 & 99 & 89570.59 & 0.797180 \\
\hline 32 & 18372.36 & 0.147685 & 66 & 33849.23 & 0.425892 & 100 & 38471.79 & 0.921815 \\
\hline 33 & 18802.93 & 0.147879 & 67 & 34996.71 & 0.429040 & 101 & 18209.13 & 0.966992 \\
\hline 34 & 19249.36 & 0.148052 & 68 & 34367.41 & 0.461079 & & & \\
\hline
\end{tabular}


Lampiran 3. Ringkasan Nilai GCV dan $R^{2}$ Regresi Nonparametrik Deret Fourier Pos Cakranegara dengan 106 Jumlah Knot

\begin{tabular}{|c|c|c|c|c|c|c|c|c|}
\hline Knot & GCV & $R^{2}$ & Knot & GCV & $R^{2}$ & Knot & GCV & $R^{2}$ \\
\hline 1 & 20183.19 & 0.002640 & 37 & 35067.41 & 0.169453 & 72 & 72811.44 & 0.443832 \\
\hline 2 & 20518.65 & 0.003321 & 38 & 35679.60 & 0.175690 & 73 & 74737.56 & 0.453671 \\
\hline 3 & 20875.71 & 0.003385 & 39 & 36536.78 & 0.176857 & 74 & 78173.25 & 0.453671 \\
\hline 4 & 21231.26 & 0.003962 & 40 & 37368.44 & 0.179299 & 75 & 78613.97 & 0.475280 \\
\hline 5 & 21556.04 & 0.006389 & 41 & 38293.80 & 0.180403 & 76 & 75459.38 & 0.519490 \\
\hline 6 & 21657.52 & 0.019302 & 42 & 39307.37 & 0.180419 & 77 & 75024.05 & 0.544741 \\
\hline 7 & 21954.41 & 0.023531 & 43 & 40298.19 & 0.181726 & 78 & 78654.68 & 0.545708 \\
\hline 8 & 22344.41 & 0.024011 & 44 & 41394.67 & 0.181726 & 79 & 82500.23 & 0.547024 \\
\hline 9 & 22665.75 & 0.027894 & 45 & 40610.84 & 0.218771 & 80 & 85034.13 & 0.556748 \\
\hline 10 & 23058.81 & 0.029099 & 46 & 41746.55 & 0.218775 & 81 & 78814.64 & 0.610506 \\
\hline 11 & 23487.03 & 0.029297 & 47 & 42713.06 & 0.222737 & 82 & 83247.35 & 0.610537 \\
\hline 12 & 23687.13 & 0.039240 & 48 & 43940.49 & 0.222766 & 83 & 87820.84 & 0.611649 \\
\hline 13 & 24099.40 & 0.040874 & 49 & 45223.21 & 0.222769 & 84 & 92826.63 & 0.612634 \\
\hline 14 & 24552.37 & 0.041371 & 50 & 43251.93 & 0.278039 & 85 & 98314.13 & 0.613513 \\
\hline 15 & 24993.84 & 0.042810 & 51 & 44465.44 & 0.279452 & 86 & 102430.30 & 0.621367 \\
\hline 16 & 25219.47 & 0.052832 & 52 & 45225.59 & 0.288847 & 87 & 103937.00 & 0.639435 \\
\hline 17 & 25712.76 & 0.053148 & 53 & 46502.94 & 0.290753 & 88 & 110242.40 & 0.641836 \\
\hline 18 & 26223.12 & 0.053382 & 54 & 46307.27 & 0.315301 & 89 & 96077.61 & 0.708319 \\
\hline 19 & 26718.62 & 0.054688 & 55 & 47788.69 & 0.315306 & 90 & 103024.30 & 0.708428 \\
\hline 20 & 26965.55 & 0.065128 & 56 & 48746.45 & 0.323579 & 91 & 110619.40 & 0.708895 \\
\hline 21 & 27521.09 & 0.065241 & 57 & 50357.77 & 0.323580 & 92 & 119292.10 & 0.708896 \\
\hline 22 & 27806.33 & 0.074926 & 58 & 51507.60 & 0.330633 & 93 & 129001.80 & 0.708951 \\
\hline 23 & 28189.40 & 0.081617 & 59 & 53244.06 & 0.330939 & 94 & 133086.80 & 0.723275 \\
\hline 24 & 28788.77 & 0.081732 & 60 & 54797.46 & 0.334563 & 95 & 119073.30 & 0.772616 \\
\hline 25 & 29293.48 & 0.085408 & 61 & 56735.46 & 0.334581 & 96 & 123757.80 & 0.783774 \\
\hline 26 & 29797.83 & 0.089561 & 62 & 56585.78 & 0.359419 & 97 & 120357.10 & 0.808398 \\
\hline 27 & 30282.96 & 0.094743 & 63 & 56647.87 & 0.381415 & 98 & 132593.30 & 0.808543 \\
\hline 28 & 30958.13 & 0.094788 & 64 & 58681.71 & 0.382295 & 99 & 146912.00 & 0.808550 \\
\hline 29 & 31622.19 & 0.095804 & 65 & 60916.95 & 0.382296 & 100 & 56412.67 & 0.934020 \\
\hline 30 & 32132.26 & 0.101750 & 66 & 62613.11 & 0.388829 & 101 & 40185.31 & 0.958077 \\
\hline 31 & 32111.34 & 0.122620 & 67 & 65087.53 & 0.388877 & 102 & 44757.44 & 0.958638 \\
\hline 32 & 31547.78 & 0.157720 & 68 & 64915.88 & 0.414157 & 103 & 50703.37 & 0.958818 \\
\hline 33 & 32264.06 & 0.158513 & 69 & 66606.78 & 0.422700 & 104 & 47559.81 & 0.966350 \\
\hline 34 & 32985.19 & 0.159828 & 70 & 69275.55 & 0.423827 & 105 & 50731.31 & 0.969051 \\
\hline 35 & 33620.26 & 0.163920 & 71 & 69916.51 & 0.442473 & 106 & 23511.64 & 0.987778 \\
\hline 36 & 34441.51 & 0.164011 & & & & & & \\
\hline
\end{tabular}


Lampiran 4. Hasil Estimasi Parameter dengan 101 Jumlah Knot Pos Selaparang

\begin{tabular}{cccccc}
\hline Parameter & Nilai Estimasi & Parameter & Nilai Estimasi & Parameter & Nilai Estimasi \\
\hline$\hat{\alpha}_{0}$ & $-249,976$ & $\hat{\alpha}_{34}$ & $-20,811$ & $\hat{\alpha}_{68}$ & 1,205 \\
$\hat{\gamma}$ & 4,651 & $\hat{\alpha}_{35}$ & 37,649 & $\hat{\alpha}_{69}$ & $-35,111$ \\
$\hat{\alpha}_{1}$ & 128,419 & $\hat{\alpha}_{36}$ & 28,462 & $\hat{\alpha}_{70}$ & 13,226 \\
$\hat{\alpha}_{2}$ & $-26,005$ & $\hat{\alpha}_{37}$ & $-1,036$ & $\hat{\alpha}_{71}$ & 18,208 \\
$\hat{\alpha}_{3}$ & $-13,844$ & $\hat{\alpha}_{38}$ & $-93,052$ & $\hat{\alpha}_{72}$ & 2,603 \\
$\hat{\alpha}_{4}$ & 36,779 & $\hat{\alpha}_{39}$ & $-17,252$ & $\hat{\alpha}_{73}$ & $-5,887$ \\
$\hat{\alpha}_{5}$ & 54,681 & $\hat{\alpha}_{40}$ & $-35,037$ & $\hat{\alpha}_{74}$ & 8,780 \\
$\hat{\alpha}_{6}$ & 92,848 & $\hat{\alpha}_{41}$ & 10,038 & $\hat{\alpha}_{75}$ & 117,019 \\
$\hat{\alpha}_{7}$ & $-15,324$ & $\hat{\alpha}_{42}$ & 29,145 & $\hat{\alpha}_{76}$ & 45,473 \\
$\hat{\alpha}_{8}$ & $-34,167$ & $\hat{\alpha}_{43}$ & $-102,912$ & $\hat{\alpha}_{77}$ & $-28,413$ \\
$\hat{\alpha}_{9}$ & $-35,461$ & $\hat{\alpha}_{44}$ & 301,717 & $\hat{\alpha}_{78}$ & 11,549 \\
$\hat{\alpha}_{10}$ & 21,721 & $\hat{\alpha}_{45}$ & $-128,787$ & $\hat{\alpha}_{79}$ & $-23,258$ \\
$\hat{\alpha}_{11}$ & $-11,555$ & $\hat{\alpha}_{46}$ & 3,303 & $\hat{\alpha}_{80}$ & $-4,144$ \\
$\hat{\alpha}_{12}$ & 153,747 & $\hat{\alpha}_{47}$ & 3,197 & $\hat{\alpha}_{81}$ & $-41,963$ \\
$\hat{\alpha}_{13}$ & 232,795 & $\hat{\alpha}_{48}$ & $-20,264$ & $\hat{\alpha}_{82}$ & $-1,276$ \\
$\hat{\alpha}_{14}$ & 32,179 & $\hat{\alpha}_{49}$ & $-46,656$ & $\hat{\alpha}_{83}$ & 6,840 \\
$\hat{\alpha}_{15}$ & 10,674 & $\hat{\alpha}_{50}$ & $-87,988$ & $\hat{\alpha}_{84}$ & 25,235 \\
$\hat{\alpha}_{16}$ & $-2,281$ & $\hat{\alpha}_{51}$ & $-5,331$ & $\hat{\alpha}_{85}$ & 10,839 \\
$\hat{\alpha}_{17}$ & 2,457 & $\hat{\alpha}_{52}$ & 41,242 & $\hat{\alpha}_{86}$ & $-34,837$ \\
$\hat{\alpha}_{18}$ & 48,055 & $\hat{\alpha}_{53}$ & 38,071 & $\hat{\alpha}_{87}$ & 52,745 \\
$\hat{\alpha}_{19}$ & $-93,845$ & $\hat{\alpha}_{54}$ & $-41,695$ & $\hat{\alpha}_{88}$ & 45,926 \\
$\hat{\alpha}_{20}$ & $-1,899$ & $\hat{\alpha}_{55}$ & 0,158 & $\hat{\alpha}_{89}$ & 82,342 \\
$\hat{\alpha}_{21}$ & $-21,995$ & $\hat{\alpha}_{56}$ & $-215,449$ & $\hat{\alpha}_{90}$ & $-0,368$ \\
$\hat{\alpha}_{22}$ & $-10,578$ & $\hat{\alpha}_{57}$ & $-193,223$ & $\hat{\alpha}_{91}$ & 16,334 \\
$\hat{\alpha}_{23}$ & 10,015 & $\hat{\alpha}_{58}$ & $-28,819$ & $\hat{\alpha}_{92}$ & 21,139 \\
$\hat{\alpha}_{24}$ & 7,622 & $\hat{\alpha}_{59}$ & 7,945 & $\hat{\alpha}_{93}$ & 35,211 \\
& & & & &
\end{tabular}




$\begin{array}{lccccc}\hat{\alpha}_{25} & 91,470 & \hat{\alpha}_{60} & 23,369 & \hat{\alpha}_{94} & 38,136 \\ \hat{\alpha}_{26} & -31,817 & \hat{\alpha}_{61} & -7,781 & \hat{\alpha}_{95} & 10,657 \\ \hat{\alpha}_{27} & -11,437 & \hat{\alpha}_{62} & -44,440 & \hat{\alpha}_{96} & -25,014 \\ \hat{\alpha}_{28} & 22,964 & \hat{\alpha}_{63} & 68,622 & \hat{\alpha}_{97} & -44,596 \\ \hat{\alpha}_{29} & 5,553 & \hat{\alpha}_{64} & 2,485 & \hat{\alpha}_{98} & 9,837 \\ \hat{\alpha}_{30} & -27,411 & \hat{\alpha}_{65} & 4,698 & \hat{\alpha}_{99} & 6,925 \\ \hat{\alpha}_{31} & -185,224 & \hat{\alpha}_{66} & -21,441 & \hat{\alpha}_{100} & 197,768 \\ \hat{\alpha}_{32} & -95,607 & \hat{\alpha}_{67} & -19,633 & \hat{\alpha}_{101} & 96,436 \\ \hat{\alpha}_{33} & 17,904 & & & & \end{array}$

Lampiran 5. Hasil Estimasi Parameter dengan 101 Jumlah Knot Pos Ampenan

\begin{tabular}{cccccc}
\hline Parameter & Nilai Estimasi & Parameter & Nilai Estimasi & Parameter & Nilai Estimasi \\
\hline$\hat{\alpha}_{0}$ & 111,047 & $\hat{\alpha}_{34}$ & $-26,656$ & $\hat{\alpha}_{68}$ & 32,621 \\
$\hat{\gamma}$ & $-0,771$ & $\hat{\alpha}_{35}$ & 8,667 & $\hat{\alpha}_{69}$ & $-40,480$ \\
$\hat{\alpha}_{1}$ & 116,747 & $\hat{\alpha}_{36}$ & 10,609 & $\hat{\alpha}_{70}$ & 25,799 \\
$\hat{\alpha}_{2}$ & $-18,068$ & $\hat{\alpha}_{37}$ & 50,891 & $\hat{\alpha}_{71}$ & 20,468 \\
$\hat{\alpha}_{3}$ & $-41,764$ & $\hat{\alpha}_{38}$ & $-139,004$ & $\hat{\alpha}_{72}$ & $-6,143$ \\
$\hat{\alpha}_{4}$ & $-13,944$ & $\hat{\alpha}_{39}$ & 25,347 & $\hat{\alpha}_{73}$ & 5,528 \\
$\hat{\alpha}_{5}$ & $-3,008$ & $\hat{\alpha}_{40}$ & 9,842 & $\hat{\alpha}_{74}$ & 0,071 \\
$\hat{\alpha}_{6}$ & 135,138 & $\hat{\alpha}_{41}$ & 22,030 & $\hat{\alpha}_{75}$ & 105,507 \\
$\hat{\alpha}_{7}$ & $-49,916$ & $\hat{\alpha}_{42}$ & 19,688 & $\hat{\alpha}_{76}$ & 19,779 \\
$\hat{\alpha}_{8}$ & $-25,413$ & $\hat{\alpha}_{43}$ & $-104,701$ & $\hat{\alpha}_{77}$ & $-12,647$ \\
$\hat{\alpha}_{9}$ & $-16,561$ & $\hat{\alpha}_{44}$ & 50,901 & $\hat{\alpha}_{78}$ & 17,468 \\
$\hat{\alpha}_{10}$ & 30,514 & $\hat{\alpha}_{45}$ & $-121,362$ & $\hat{\alpha}_{79}$ & 0,733 \\
$\hat{\alpha}_{11}$ & $-16,116$ & $\hat{\alpha}_{46}$ & 0,000 & $\hat{\alpha}_{80}$ & $-13,164$ \\
$\hat{\alpha}_{12}$ & 94,258 & $\hat{\alpha}_{47}$ & 31,032 & $\hat{\alpha}_{81}$ & $-45,164$ \\
$\hat{\alpha}_{13}$ & 220,712 & $\hat{\alpha}_{48}$ & 22,887 & $\hat{\alpha}_{82}$ & 33,598 \\
$\hat{\alpha}_{14}$ & 4,922 & $\hat{\alpha}_{49}$ & $-0,385$ & $\hat{\alpha}_{83}$ & $-15,818$ \\
$\hat{\alpha}_{15}$ & 3,360 & $\hat{\alpha}_{50}$ & $-125,965$ & $\hat{\alpha}_{84}$ & 2,685 \\
$\hat{\alpha}_{16}$ & $-5,559$ & $\hat{\alpha}_{51}$ & 24,853 & $\hat{\alpha}_{85}$ & 0,734 \\
$\hat{\alpha}_{17}$ & 4,071 & $\hat{\alpha}_{52}$ & 34,286 & $\hat{\alpha}_{86}$ & $-14,776$ \\
$\hat{\alpha}_{18}$ & 59,224 & $\hat{\alpha}_{53}$ & 11,269 & $\hat{\alpha}_{87}$ & 51,130 \\
$\hat{\alpha}_{19}$ & $-117,095$ & $\hat{\alpha}_{54}$ & $-36,500$ & $\hat{\alpha}_{88}$ & $-39,471$ \\
$\hat{\alpha}_{20}$ & 54,387 & $\hat{\alpha}_{55}$ & 20,922 & $\hat{\alpha}_{89}$ & 75,194 \\
& & & & &
\end{tabular}




$\begin{array}{lccccc}\hat{\alpha}_{21} & 30,447 & \hat{\alpha}_{56} & -146,002 & \hat{\alpha}_{90} & -16,146 \\ \hat{\alpha}_{22} & -4,201 & \hat{\alpha}_{57} & -176,351 & \hat{\alpha}_{91} & -11,495 \\ \hat{\alpha}_{23} & -38,900 & \hat{\alpha}_{58} & -3,132 & \hat{\alpha}_{92} & 3,564 \\ \hat{\alpha}_{24} & -42,644 & \hat{\alpha}_{59} & 13,913 & \hat{\alpha}_{93} & 5,353 \\ \hat{\alpha}_{25} & 96,850 & \hat{\alpha}_{60} & 16,952 & \hat{\alpha}_{94} & 54,011 \\ \hat{\alpha}_{26} & -36,769 & \hat{\alpha}_{61} & -8,219 & \hat{\alpha}_{95} & -3,149 \\ \hat{\alpha}_{27} & -2,647 & \hat{\alpha}_{62} & -53,949 & \hat{\alpha}_{96} & -15,756 \\ \hat{\alpha}_{28} & 19,506 & \hat{\alpha}_{63} & 87,275 & \hat{\alpha}_{97} & -15,741 \\ \hat{\alpha}_{29} & 4,797 & \hat{\alpha}_{64} & -43,648 & \hat{\alpha}_{98} & 2,398 \\ \hat{\alpha}_{30} & -10,346 & \hat{\alpha}_{65} & -19,403 & \hat{\alpha}_{99} & -21,336 \\ \hat{\alpha}_{31} & -163,979 & \hat{\alpha}_{66} & -11,971 & \hat{\alpha}_{100} & 153,990 \\ \hat{\alpha}_{32} & -53,024 & \hat{\alpha}_{67} & 17,886 & \hat{\alpha}_{101} & 81,864 \\ \hat{\alpha}_{33} & 22,949 & & & & \end{array}$

Lampiran 6. Hasil Estimasi Parameter dengan 106 Jumlah Knot Pos Cakranegara

\begin{tabular}{cccccc}
\hline Parameter & Nilai Estimasi & Parameter & Nilai Estimasi & Parameter & Nilai Estimasi \\
\hline$\hat{\alpha}_{0}$ & $-55,110$ & $\hat{\alpha}_{35}$ & 18,305 & $\hat{\alpha}_{71}$ & 39,363 \\
$\hat{\gamma}$ & 1,928 & $\hat{\alpha}_{36}$ & 31,162 & $\hat{\alpha}_{72}$ & 7,452 \\
$\hat{\alpha}_{1}$ & 211,311 & $\hat{\alpha}_{37}$ & 51,017 & $\hat{\alpha}_{73}$ & 38,503 \\
$\hat{\alpha}_{2}$ & $-57,173$ & $\hat{\alpha}_{38}$ & $-179,240$ & $\hat{\alpha}_{74}$ & 8,596 \\
$\hat{\alpha}_{3}$ & 7,665 & $\hat{\alpha}_{39}$ & 48,616 & $\hat{\alpha}_{75}$ & 124,142 \\
$\hat{\alpha}_{4}$ & 54,124 & $\hat{\alpha}_{40}$ & $-44,839$ & $\hat{\alpha}_{76}$ & 40,217 \\
$\hat{\alpha}_{5}$ & $-29,122$ & $\hat{\alpha}_{41}$ & $-1,945$ & $\hat{\alpha}_{77}$ & $-11,963$ \\
$\hat{\alpha}_{6}$ & 188,699 & $\hat{\alpha}_{42}$ & 62,306 & $\hat{\alpha}_{78}$ & 8,352 \\
$\hat{\alpha}_{7}$ & $-47,772$ & $\hat{\alpha}_{43}$ & $-182,308$ & $\hat{\alpha}_{79}$ & $-3,037$ \\
$\hat{\alpha}_{8}$ & $-43,826$ & $\hat{\alpha}_{44}$ & 204,885 & $\hat{\alpha}_{80}$ & $-18,637$ \\
$\hat{\alpha}_{9}$ & $-18,999$ & $\hat{\alpha}_{45}$ & $-198,766$ & $\hat{\alpha}_{81}$ & $-66,134$ \\
$\hat{\alpha}_{10}$ & 20,560 & $\hat{\alpha}_{46}$ & 29,516 & $\hat{\alpha}_{82}$ & 59,710 \\
$\hat{\alpha}_{11}$ & 28,290 & $\hat{\alpha}_{47}$ & 1,472 & $\hat{\alpha}_{83}$ & $-21,400$ \\
$\hat{\alpha}_{12}$ & 121,080 & $\hat{\alpha}_{48}$ & $-36,300$ & $\hat{\alpha}_{84}$ & 35,493 \\
$\hat{\alpha}_{13}$ & 276,589 & $\hat{\alpha}_{49}$ & 20,436 & $\hat{\alpha}_{85}$ & 17,342 \\
$\hat{\alpha}_{14}$ & 27,266 & $\hat{\alpha}_{50}$ & $-180,093$ & $\hat{\alpha}_{86}$ & $-45,364$ \\
$\hat{\alpha}_{15}$ & 43,119 & $\hat{\alpha}_{51}$ & 10,447 & $\hat{\alpha}_{87}$ & 91,282 \\
$\hat{\alpha}_{16}$ & 39,601 & $\hat{\alpha}_{52}$ & 59,407 & $\hat{\alpha}_{88}$ & $-7,160$
\end{tabular}




\begin{tabular}{lccccc}
$\hat{\alpha}_{17}$ & $-17,278$ & $\hat{\alpha}_{53}$ & 6,812 & $\hat{\alpha}_{89}$ & 103,527 \\
$\hat{\alpha}_{18}$ & 162,554 & $\hat{\alpha}_{54}$ & $-38,234$ & $\hat{\alpha}_{90}$ & $-4,820$ \\
$\hat{\alpha}_{19}$ & $-142,843$ & $\hat{\alpha}_{55}$ & $-26,219$ & $\hat{\alpha}_{91}$ & 7,071 \\
$\hat{\alpha}_{20}$ & 55,537 & $\hat{\alpha}_{56}$ & $-192,344$ & $\hat{\alpha}_{92}$ & 24,349 \\
$\hat{\alpha}_{21}$ & $-14,728$ & $\hat{\alpha}_{57}$ & $-217,946$ & $\hat{\alpha}_{93}$ & 4,667 \\
$\hat{\alpha}_{22}$ & $-12,133$ & $\hat{\alpha}_{58}$ & $-23,100$ & $\hat{\alpha}_{94}$ & 55,500 \\
$\hat{\alpha}_{23}$ & 12,860 & $\hat{\alpha}_{59}$ & $-28,138$ & $\hat{\alpha}_{95}$ & 12,650 \\
$\hat{\alpha}_{24}$ & $-59,081$ & $\hat{\alpha}_{60}$ & $-15,773$ & $\hat{\alpha}_{96}$ & $-24,246$ \\
$\hat{\alpha}_{25}$ & 133,027 & $\hat{\alpha}_{61}$ & 32,786 & $\hat{\alpha}_{97}$ & $-27,147$ \\
$\hat{\alpha}_{26}$ & $-131,090$ & $\hat{\alpha}_{62}$ & $-152,061$ & $\hat{\alpha}_{98}$ & 0,859 \\
$\hat{\alpha}_{27}$ & 8,875 & $\hat{\alpha}_{63}$ & 103,792 & $\hat{\alpha}_{99}$ & 23,158 \\
$\hat{\alpha}_{28}$ & $-8,840$ & $\hat{\alpha}_{64}$ & $-50,561$ & $\hat{\alpha}_{100}$ & 194,779 \\
$\hat{\alpha}_{29}$ & $-24,124$ & $\hat{\alpha}_{65}$ & 12,123 & $\hat{\alpha}_{101}$ & 93,576 \\
$\hat{\alpha}_{30}$ & $-26,416$ & $\hat{\alpha}_{66}$ & $-14,171$ & $\hat{\alpha}_{102}$ & 17,040 \\
$\hat{\alpha}_{31}$ & $-194,539$ & $\hat{\alpha}_{67}$ & $-20,150$ & $\hat{\alpha}_{103}$ & 13,341 \\
$\hat{\alpha}_{32}$ & $-58,721$ & $\hat{\alpha}_{68}$ & 50,850 & $\hat{\alpha}_{104}$ & 46,706 \\
$\hat{\alpha}_{33}$ & $-5,890$ & $\hat{\alpha}_{69}$ & $-73,349$ & $\hat{\alpha}_{105}$ & $-18,813$ \\
$\hat{\alpha}_{34}$ & $-12,281$ & $\hat{\alpha}_{70}$ & 49,998 & $\hat{\alpha}_{106}$ & 70,230 \\
\hline
\end{tabular}

